\title{
FASCIAE OF THE MASTICATOR SPACE
}

\author{
GEORGE R. L. GAUGHRAN \\ Department of Anatomy, University of Michigan, Ann Arbor, Michigan
}

SIX FIGURES

\section{INTRODUCTION}

In the course of dissections of the fasciae related to the muscles of mastication in 50 half heads, it was noted that a fascial condensation covered the external surface of the lateral pterygoid, the pyramidal fibers of the medial pterygoid, and the anteromedial surface of the temporal muscles. A number of workers have reported the presence of one or more of these fasciae but the accounts give little detail concerning their attachments and relations.

Juvara (1895) noted what he termed an external aponeurosis of the lateral pterygoid muscle. Forster ('04), Gilis and Peyron ('05), and Eisler ('12) indicated a fascial covering of this muscle. Hovelacque and Virenque ('13) and Sedan and De Vernéjoul ('14) described a vascular layer which may be comparable to the lateral pterygoid fascia. In this country, Coller and Yglesias ('35) described the fused superficial and middle cervical fasciae as having a deep layer which forms the sheaths for the lateral and medial pterygoid muscles. Grodinsky and Holyoke ('38) indicated that these sheaths were formed by the superficial layer of cervical fascia. Dingman ('39) also mentioned these sheaths for the lateral and medial pterygoid muscles but related them to the middle layer of cervical fascia. Forster ('04), Eisler ('12), and Sloman ('39) noted that a connective tissue condensation covered the deep surface of the temporal muscle. Of the American and British texts, only Morris and Gray mention a fascia around 
the lateral pterygoid muscle. Very recently, Zenker ('55a, '55b) described the temporal muscle and some portions of the deep temporal fascia.

The total information available today on these fascial planes is so sketchy that one cannot obtain a clear understanding of their extent or determine exactly how they enclose certain structures to form compartments. The masticator space is described as a fascial compartment containing the temporal, masseter, lateral and medial pterygoid muscles, the temporomandibular joint, the ramus of the mandible, the corpus adiposum buccae, and certain neurovascular structures. It is delimited by the upward entension of the superficial lamina of the cervical fascia which attaches to the lower border of the mandible. From this attachment a deep plane passes upward on the inside of the medial pterygoid muscle, (i.e., medial pterygoid fascia), to attach to the skull. A superficial sheet covers the masseter muscle (masseteric fascia), to attach to the lower border of the zygomatic arch. From the upper border of the zygomatic arch a plane continues superiorly, covering the temporal muscle (temporal fascia or temporal aponeurosis of Batson, '53) and attaches to the superior temporal line. Posteriorly the superficial and deep laminae attach to the rear edge of the ramus of the mandible. The anterior attachment of the superficial leaf is not as clearly agreed upon.

Juvara (1895) stated that the masseteric fascia attached by a deep leaf to the anterior border of the ramus of the mandible and by a superficial leaf to the buccinator fascia. Coller and Yglesias ('35) illustrated its attachment to the maxilla. Grodinsky and Holyoke ('38) stated that this layer passed around the anterior border of the ramus and became continuous with the sheath of the lateral pterygoid muscle. Dingman ('39) indicated that the superficial and deep leaves fuse along the anterior border of the masseter muscle. Bransby-Zachary ('48) confirmed Juvara's findings.

The purpose of this report is to re-evaluate the anterior boundary of the masticator space and to describe the fasciae 


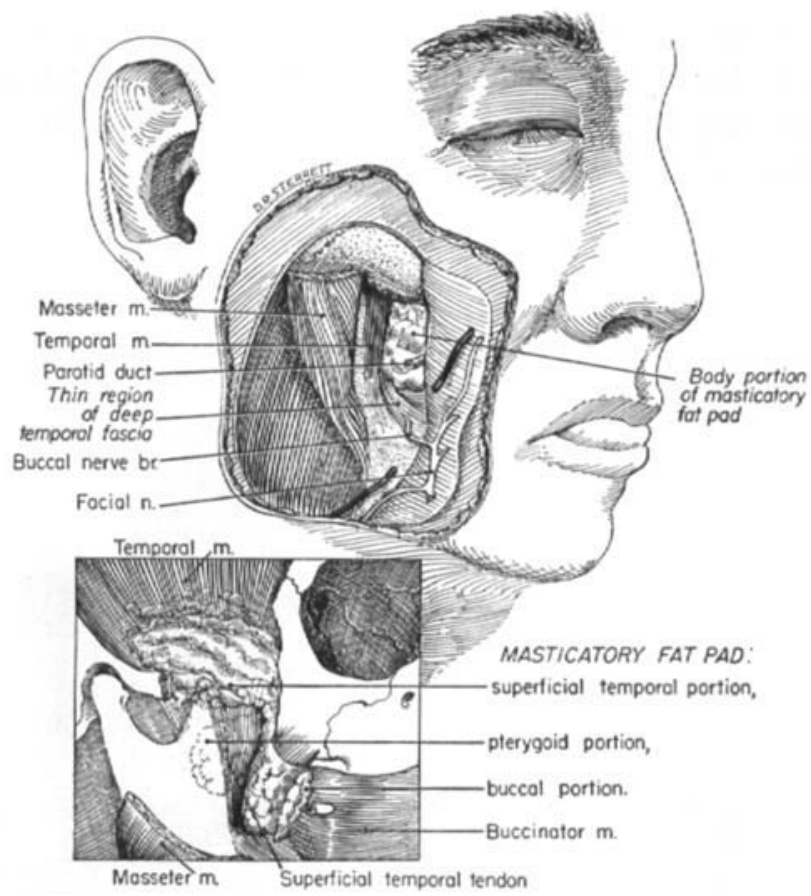

Fig. 1 Oblique view of the head illustrating a lateral approach for exposure of the masticatory fat pad and the fasciae within the masticator space. Insert illustrates a more advanced dissection with the removal of the masseter muscle and zygomatic arch, (pterygoid portion of fat pad is deep to ramus).

covering the external surface of the lateral pterygoid and the anteromedial surface of the temporal muscles. These two layers will be shown to participate not only in delimiting but also in compartmentalizing the masticator space. In addition, they isolate the greater portion of the corpus adiposum buccae from the masticatory muscles. Consequently, a detailed description of the form and relation of the fat pad will be necessary.

\section{DESCRIPTION}

The corpus adiposum buccae, better termed the "masticatory fat pad" (Sicher, '52), consists of a body and four extensions. In the adult the "body" or main mass of the 
fat pad rests on the maxillary periosteum and the upper, more posterior fibers of the buccinator muscle (figs. 1,2, and 3). It extends from the pterygopalatine fossa to the medial surface of the masseter muscle.

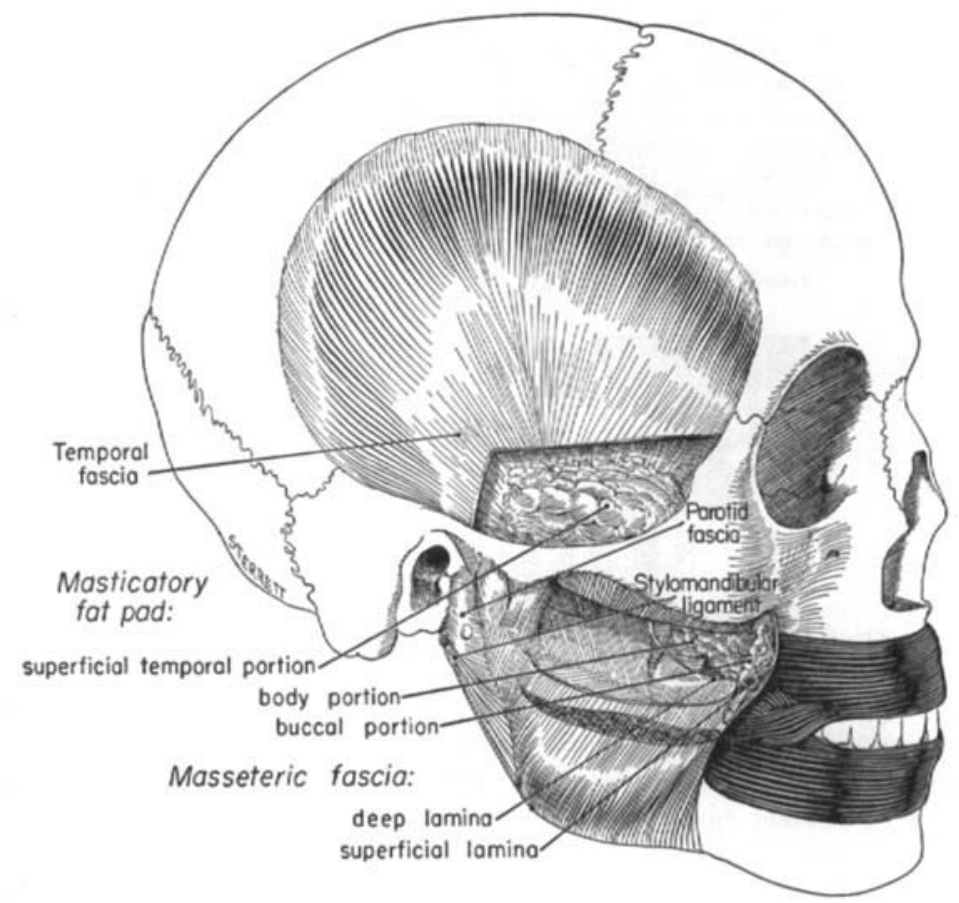

Fig. 2 Schematized dissection of masticator space showing the relations of the anterior part of the masseteric fascia to the masticatory fat pad.

Extending from the anterior extremity of the body of the masticatory fat pad is a blunt rounded "buccal" process (figs. 1, 2, and 3). It rests on the buccinator fascia and muscle and projects laterally at the anterior border of the masseter muscle. In the infant this process is as large as or larger than the body but, in the adult, it is very much reduced in size. This portion alone merits the term "corpus adiposum buccae" (Scammon, '19).

A second projection of the fat pad, the "pterygopalatine" process, is a direct extension of its body into the pterygopala- 
tine fossa where it envelops the neurovascular structures in the fossa. A thin extension from the upper pole of this process follows along the maxillary division of the trigeminal nerve to enter the cranial vault through foramen rotundum.

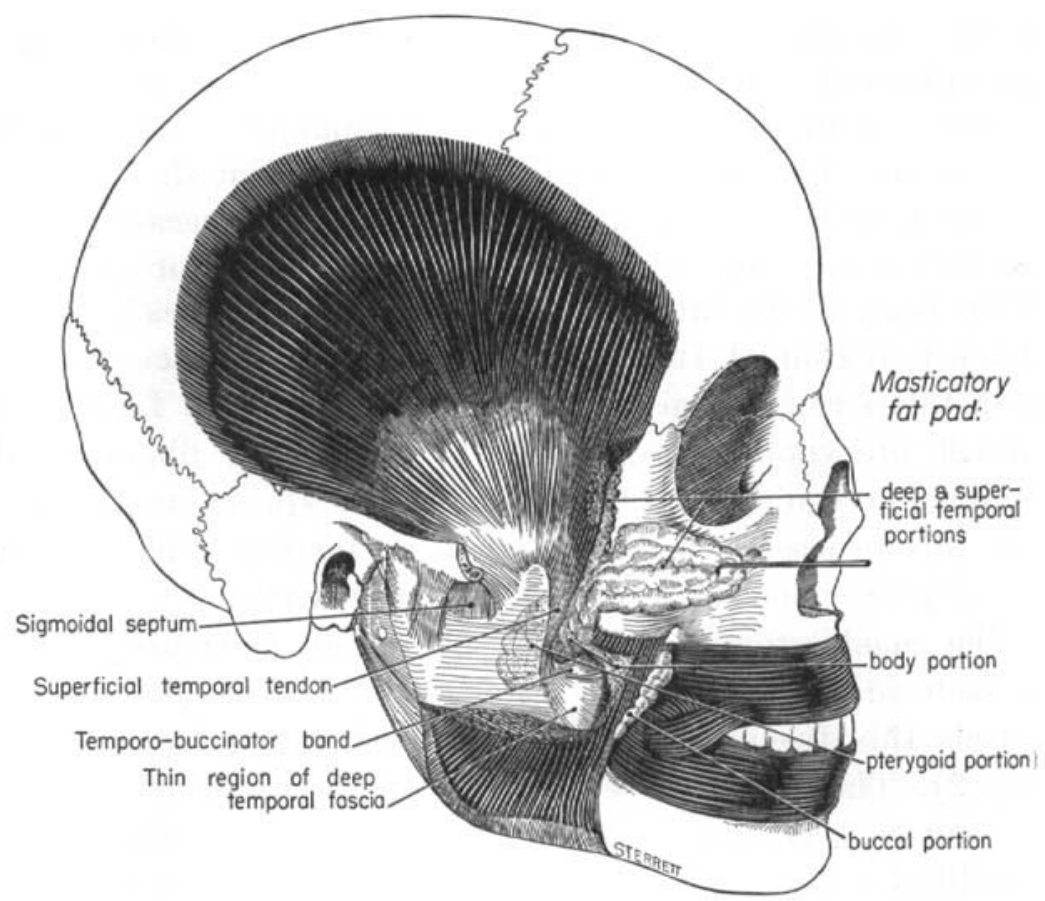

Fig. 3 Sehematized deeper dissection in which the zygomatic arch and the major portion of the masseter muscle have been removed to show a part of the deep temporal faseia, (the superficial temporal portion of the fat pad has been turned forward).

The largest extension is the "temporal" process which passes superiorly from the upper part of the body to lie between the anterior margin of the temporal muscle and the temporal surface of the zygomatic bone (figs. 1, 2, and 3 ). It splits into two portions. The superficial part, a prominent process, passes upward and backward between the temporal fascia and the surface of the temporal muscle. In fact muscle fibers originating from the temporal fossa pass through its 
lateral surface and bind it to the muscle. The deep portion is a narrow tongue of variable length $(1+\mathrm{cm})$ which passes superiorly between the superficial and deep fibers of the temporal muscle. It rests on the greater wing of the sphenoid between muscle fibers originating from the temporal surface of the zygomatic bone and fibers from the greater wing of the sphenoid (fig. 3). The temporal extension is the only process of the fat pad which is intimately related to the masticatory muscle and cannot be readily isolated.

The fourth extension, the "pterygoid" process, extends downward and backward from the lower posterior extremity of the body of the fat pad (figs. 1 and 3). It passes backward above a region of fusion of the buccinator muscle and the deep temporal tendon and rests on the external face of the lateral pterygoid muscle and the pyramidal fibers of the medial pterygoid muscle. In none of the specimens dissected was this process extensive, and in no instance did it extend as far posterior as the inferior alveolar nerve.

The masticatory fat pad is delimited anteriorly by the masseteric fascia. At the anterior border of the masseter muscle this fascia splits into a superficial and a deep leaf (fig. 2). The deep leaf reflects around the anterior border of the muscle and passes toward the anterior border of the mandibular ramus; here it blends with the insertion of the superficial part of the temporal muscle and attaches to the oblique line of the mandible. Superiorly, deep to the zygomatic arch, it blends with the fascia on the lateral surface of the temporal process of the fat pad and fans out on the epimysium of the temporal muscle above the level of the zygomatic arch. The superficial lamina attaches to the maxilla along the zygomatico-alveolar erest. Thence it blends with the buccinator fascia along a line from the second maxillary molar to the third mandibular molar to meet the attachment of the deep leaf along the oblique line. The buccal process of the fat pad rests between the superficial and deep leaves of the masseteric fascia. The superficial leaf not only limits the buccal process 
of the fat pad but also forms the anterior wall of the masticator compartment.

Although the pterygoid process and the body of the fat pad rest against the muscles of mastication, they are separated from them by a fascia of variable thickness. Hence the masticatory fat pad is limited posteriorly by a plane of fascia covering the external surface of the lateral pterygoid muscle

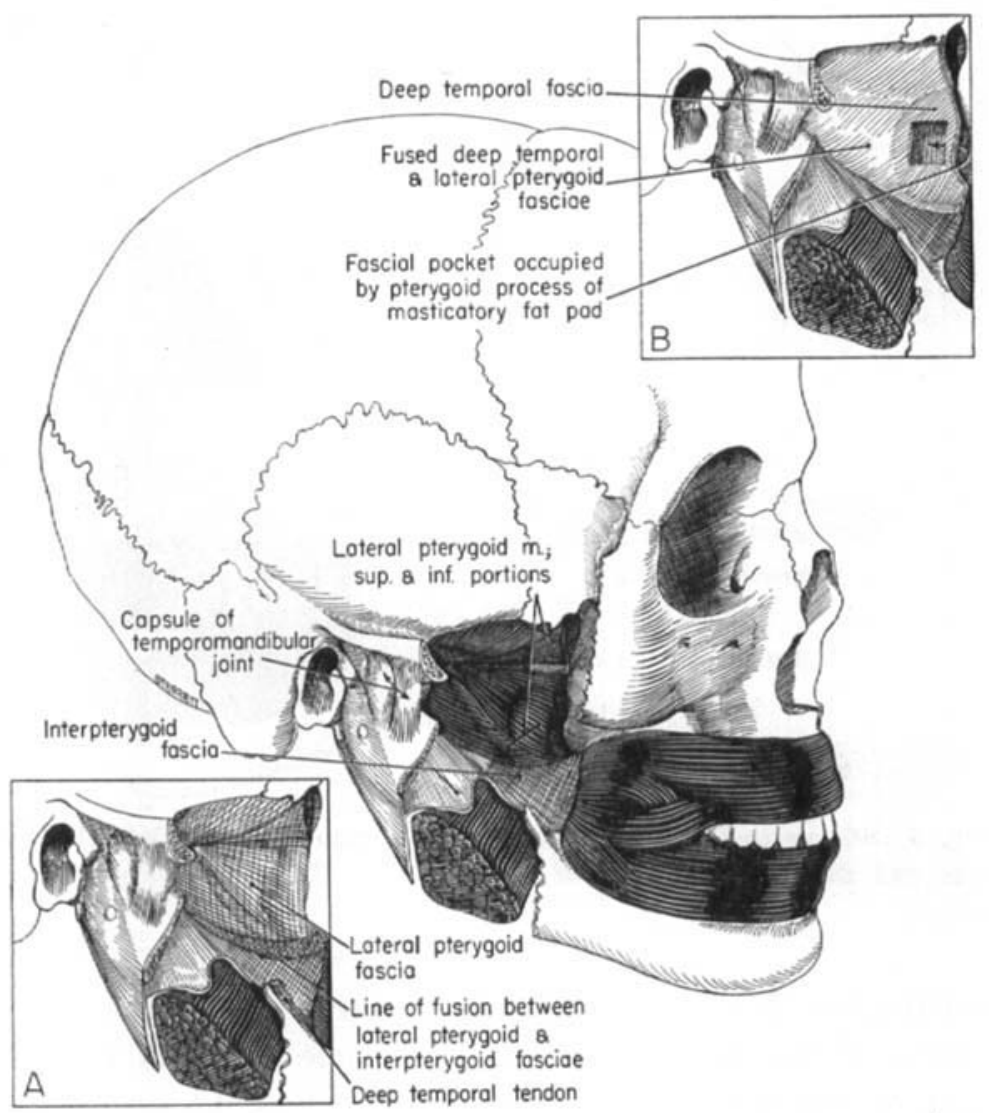

Fig. 4 Schematized deeper dissection in which the temporal muscle and the ramus of the mandible, excluding the condyle and neck, have been removed to illustrate the pterygoid muscles and the interpterygoid fascia. A. The lateral pterygoid faseia and deep temporal tendon are shown. B. The deep temporal faseia is illustrated. 
and a plane of fascia on the anterior and medial surfaces of the temporal muscle (figs. 4A and 4B). These two sheets are clearly separated from one another anteriorly, but they are intimately united more posteriorly. The first plane may be called the "lateral pterygoid fascia." It is usually a thin, but

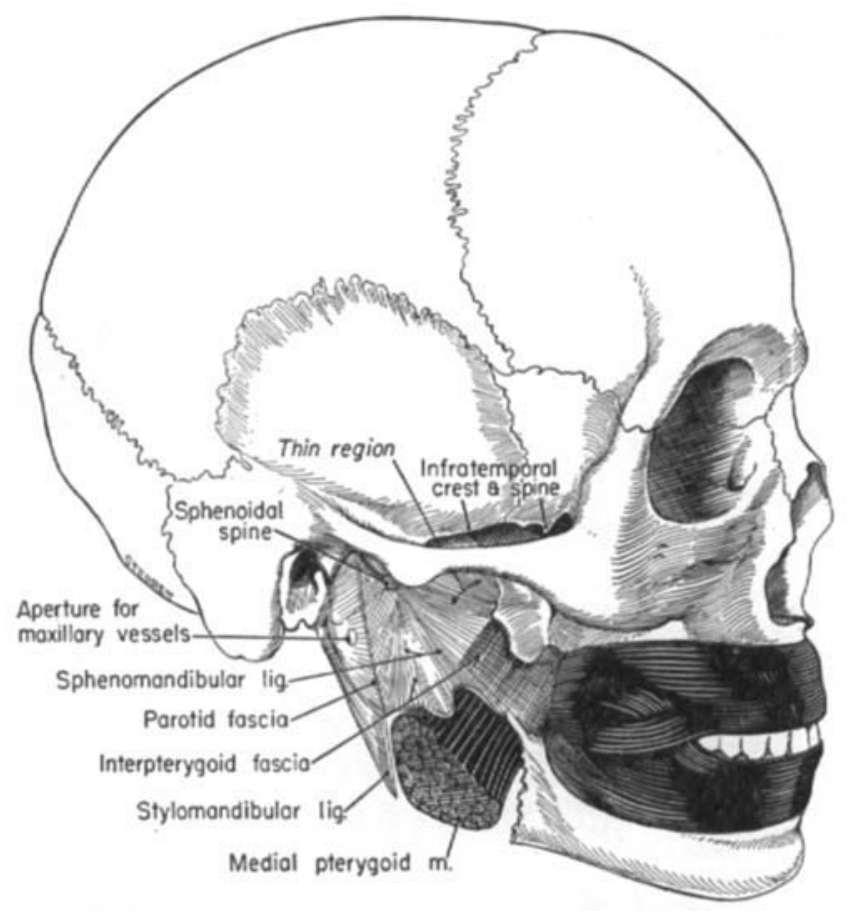

Fig. 5 Sehematized deeper dissection after removal of the lateral pterygoid muscle and the head and neck of the mandible. The interpterygoid fascia is shown.

nevertheless discrete, layer lying directly on the external surface of the lateral pterygoid muscle and the pyramidal origin of the medial pterygoid muscle (figs. $4 \mathrm{~A}$ and $\mathrm{B}$ ).

The lateral pterygoid fascia can be described as a triangular sheet which has an anterior attachment along a more or less vertical ridge on the lateral pterygoid plate behind the pterygopalatine fossa; its superior edge attaches along the 
infratemporal crest; and, a lower edge attaches obliquely to the inner surface of the ramus of the mandible.

Superiorly, the attachment of this fascial layer to the infratemporal crest extends from the lateral part of the capsule of the temporomandibular joint to the infratemporal spine anteriorly. The anterior, vertical edge of the fascia attaches in sequence: (1) to the infratemporal spine, (2) to the bony ridge (sphenomaxillary crest of Henle, 1871) between the sphenomaxillary and infratemporal surfaces of the sphenoid bone, (3) to the vertical crest immediately behind the pterygopalatine fossa, (4) to the sphenomaxillary suture, (5) to the maxilla directly in front of the pyramidal process of the palatine bone, and (6) to the buccinator fascia down to the region of the apex of the retromolar trigone. The lower oblique edge of the fascia attaches to the medial surface of the mandibular ramus. This line of attachment from front to back extends: (1) from the retromolar trigone, (2) across the base of the coronoid process below the attachment of the tendon and muscle fibers of the deep and superficial parts of the temporal muscle, (3) to the midregion of the mandibular notch, and (4) along the rim of the notch to fuse with the lateral part of the capsule of the temporomandibular joint. It blends with the inferior attachment of the more medially placed interpterygoid fascia (figs. $4 \mathrm{~A}$ and 5). The lateral pterygoid fascia forms a pathway for the temporal branches of the maxillary artery and the pterygoid venous plexus, hence the French term "vascular fascia." The fascia isolates the pterygoid muscles from the more superficial masticatory muscles and also forms the medial wall of a fascial pocket which makes up the posterior boundary of the masticatory fat pad. The pterygoid process of the fat pad rests in this pocket.

The lateral wall of this pocket is formed by a second plane designated here as the "deep temporal fascia," a term used in Gray's Anatomy (p. 427). It lies on the anterior and medial surfaces of the superficial and deep portions of the temporal muscle (figs. 4B and 6). 
The temporal muscle originates from the temporal fascia and the temporal fossa. The latter origin extends from the inferior temporal line to the lip of the infratemporal crest and spine. An additional origin, not generally recognized, is in the anterior region of the temporal fossa from the sphenofrontal process of the zygomatic bone, extending about $2 \mathrm{~cm}$

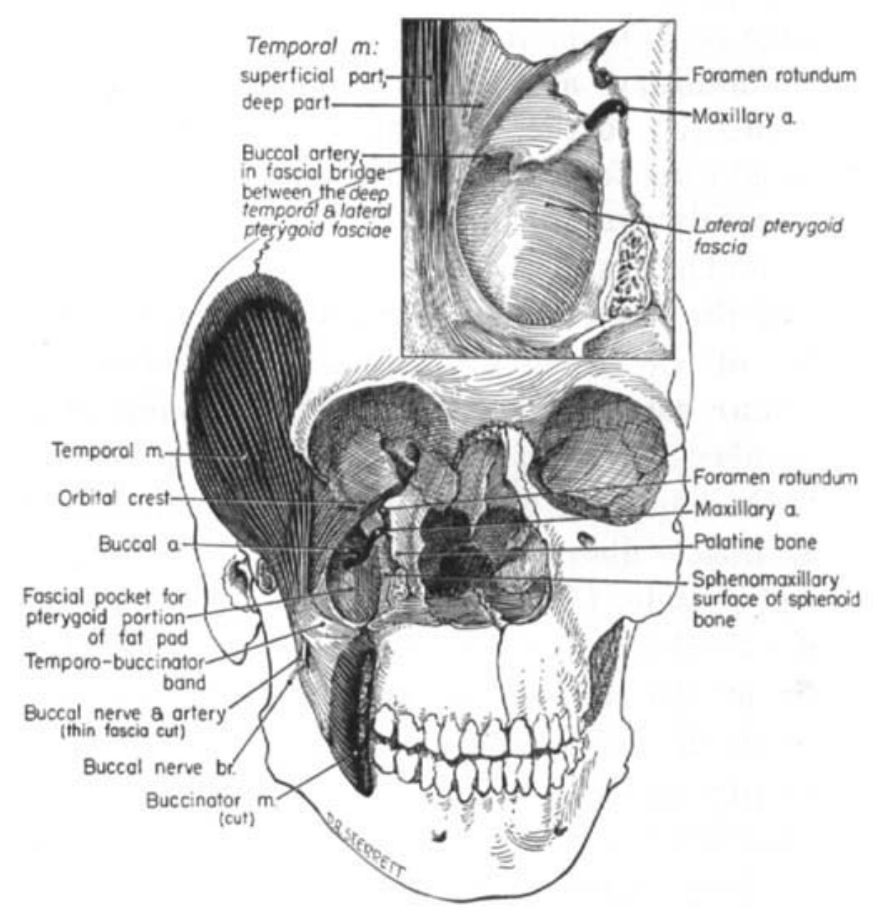

Fig. 6 Oblique view of the skull showing temporal muscle and fascial pocket deep to muscle. Insert is an enlarged sketch of the pocket showing buccal artery in the fascial roof.

inferior to the marginal tubercle of the zygoma. In addition, Zenker ('55a) described an origin from the sphenomaxillary surface of the sphenoid bone lateral to the foramen rotundum (fig. 6). This origin was observed in all of the specimens dissected.

The temporal muscle inserts by a superficial and a deep tendon. The fibers of the muscle which form the tendons are 
intimately related and a complete and distinct separation between the two portions does not exist. The superficial portion, originating from the temporal fossa and fascia, forms a tendon which inserts along the anterior and posterior edges and adjacent lateral and medial surfaces of the coronoid process of the mandible. The deep tendon is formed from fibers originating from the infratemporal crest and the sphenomaxillary surface of the sphenoid bone. This attaches to a ridge which begins at the posterior apex of the retromolar trigone and arches upward on the ramus of the mandible to the medial surface of the coronoid process. The muscle insertion is about 2.5 to $3 \mathrm{~cm}$ in length. The ridge just described, not named in the standard texts, can be identified as the "temporal crest" (Sicher, '52). Between the attachments of the superficial and deep tendons is a bare, concave area of bone, the retromolar fossa. Buccinator muscle fasciculi are directly continuous with the lowest 2 or $3 \mathrm{~mm}$ of the attachment of the deep temporal tendon. This continuity was indicated by Hovelacque ('14) and Zenker ('55a).

The deep temporal fascia is usually dissectable as a discrete layer on the deep tendon up to its attachment to the ridge forming the lateral border of the inferior orbital fissure. This ridge, the "orbital crest" (Henle, 1871), separates the orbital surface from the sphenomaxillary surface of the sphenoid. As the fascia covers the anterior surface of the superficial tendon it becomes thinner and blends with the epimysium above the level of the coronoid process. Inferiorly, the fascia sweeps downward to cover the surface of the superficial and deep tendons and attaches along the oblique line of the mandible and to the buccinator fascia (figs. 1, 3, and 6).

Within this plane of fascia covering the surface of the superficial and deep tendons is a prominent regional condensation about $1 \mathrm{~cm}$ wide and $2 \mathrm{~cm}$ long which passes downward and inward. It extends from the medial surface of the superficial tendon at its attachment to the anterior edge of the coronoid process to the buccinator fascia (figs. 1, 3, and 6). The term "temporo-buccinator" band is suggested to identify this 
fascial condensation. The band begins on the anteromedial surface of the tendon of the superficial head of the temporal muscle about $2 \mathrm{~cm}$ below the apex of the coronoid process and attaches to the buccinator fascia a little anterior to the pterygomandibular raphe. The line of temporal attachment as well as that along the buccinator muscle is oblique and passes from above, downward, and forward. Its temporal origin, continuous with the epimysium and perimysium of the superficial head of the temporal muscle, as well as with the superficial tendon, is at the level of the most superior fibers of the buccinator muscle. It inserts into buccinator fascia, but its fibers also decussate with the fasciculi of the buccinator muscle. In fact, some buccinator muscle fasciculi originate directly from the band.

From the medial edge of the anterior border of the deep tendon, the deep temporal fascia continues posteriorly to cover the inner surface of the temporal muscle below the level of the infratemporal crest. It passes backwards as a separate plane for a variable distance before it fuses with the lateral pterygoid fascia to form a single fascial plane (fig. 4B). Because of this fusion we can consider the attachment of the deep temporal fascia to the base of the skull as being identical with that of the lateral pterygoid fascia. Similarly, its attachment inferiorly to the ramus follows that of the lateral pterygoid fascia.

Morris' Human Anatomy describes a sigmoidal septum which occupies the mandibular notch. Despite the fact that this septum was described as early as 1895 by Juvara, it has not been related to any fascial plane. The septum is formed by the posterior portion of these two fused fasciae (figs. 3, 4A and B). It does not, however, attach to the entire extent of the mandibular notch; usually it extends over only its posterior half, i.e., behind the attachment of the rearmost temporal fibers. It is penetrated by the masseteric nerve and vessels.

Superiorly, the area of fusion between the deep temporal and lateral pterygoid fasciae is usually in the region of the 
cleft between the two heads of the lateral pterygoid muscle (fig. 6, insert). Within this fascial bridge are the buccal nerve and artery together with several anterior deep temporal branches of the mandibular division of the trigeminal nerve. These branches are in addition to the anterior deep temporal nerve passing above the upper head of the lateral pterygoid muscle. Superior to this region of fusion, the two fasciae usually remain united, though a small space may persist beneath the sphenomaxillary portion of the temporal muscle. This space is occupied by a portion of the temporal process of the masticatory fat pad.

The buccal nerve emerges superior to the upper head or between the upper and lower heads of the lateral pterygoid muscle. It passes laterally, within the zone of fusion between the lateral pterygoid and deep temporal fasciae, to lie against or imbedded within the most medial fibers of the deep part of the temporal muscle. In its downward course it is bounded first by temporal muscle fibers laterally and the deep temporal fascia medially. Then it lies between the deep temporal tendon laterally and the temporo-buecinator band medially. Finally, it passes between a thin portion of the deep temporal fascia laterally and the buccinator fascia medially. If one removes or breaks through this thin portion of the deep temporal fascia, one creates a triangular interspace bounded by the oblique line of the mandible, the temporo-buccinator band, and the buccinator fascia. Through this interval the buccal nerve can be seen as it passes forward on the buccinator fascia (fig. 6).

The buccal artery, given off from the second part of the maxillary artery, arises close to the anterior deep temporal artery in the anterior region of the cleft between the two heads of the lateral pterygoid muscle and within the region of fusion between the lateral pterygoid fascia and the deep temporal fascia. The artery passes laterally through the fascia of this union to reach the medial side of the deep surface of the temporal muscle and then follows the course of the buccal nerve. 


\section{DISCUSSION}

Much has been written concerning fasciae and controversy has occasionally arisen as to the existence of true fascial planes. There can be little doubt, however, that connective tissue condensations of variable density do exist and, further, that these planes may act as barriers to the spread of infection. The masticator space represents a definite fascial compartment the boundaries of which resist the spread of infection from or into the region. It is equally true that a purulent fluid in this space is not free to pass throughout the extent of the compartment. For instance, the interpterygoid fascia separates a deep space (that of the medial pterygoid muscle) and a more superficial space around the remaining masticatory muscles. The spread of infection is further confined to a degree by the lateral pterygoid, deep temporal, and masseteric fasciae. These fasciae isolate a region surrounding the lateral pterygoid muscle which cuts off the temporal and masseter muscles from the pterygoid portion of the space. Kostrubala ('45) described an infratemporal space bounded laterally by the ramus of the mandible and medially by the medial pterygoid fascia. This space, he stated, is in free communication with the space superficial to the buccinator muscle and occupied by the masticatory fat pad. Actually, on the basis of the attachments of the lateral pterygoid and deep temporal fasciae, the pterygoid compartment is not open to the masticatory fat pad. In addition, the mandibular notch is not an open pathway for the spread of fluids from the region deep to the mandible to the space of the masseter muscle but is closed by the sigmoidal septum. To effect proper drainage with a minimum of tissue destruction the compartmentalization of the masticator space should be understood before incisions are made for its drainage.

The masticatory fat pad has been interpreted here as consisting of a "body" from which there are four main extensions, referred to as buccal, pterygopalatine, pterygoid, and temporal processes. Earlier reports on the form of the fat 
pad were those of Forster ('04) and Franceschini ('51). The terminology used by these workers differs somewhat from that reported here. These men refer to the "buccal" process as the "masseter pad" and "nodule" and to the "body" as the "principal part"' and "peduncle." Despite the discrepancies in terminology there is an agreement concerning the basic morphology of the masticatory fat pad.

The introduction of a contaminated needle in the process of inferior alveolar or buccal nerve anesthesia presents the possibility of carrying pathogenic organisms into the space occupied by the masticatory fat pad. On the basis of the fascial boundaries described in this paper, several avenues of spread can be anticipated. The infection is free to pass into the pterygopalatine fossa or to flow external to the fat pad into the space between the temporal muscle and the temporal fascia (superficial temporal space of Coller and Yglesius, '35) and to gravitate downward lateral to the sigmoidal septum into the masseteric space. Batson ('53) did not recognize the superficial temporal space, but, rather, considered an infection here as a purulent temporal myositis. This is true since the more lateral portion of the temporal muscle does originate from the temporal fascia. However, there is a region extending from 4 to $5 \mathrm{~cm}$ above the level of the zygomatic arch where a space exists between the muscle and the fascia. This space is occupied by the superficial part of the temporal process of the masticatory fat pad. Another pathway of spread is along the deep part of the temporal process of the fat pad to infiltrate between the temporal muscle and the temporal and sphenoid bones (deep temporal space of Coller and Yglesius, '35). An infection in the space of the fat pad would be prevented from spreading directly to the lateral and medial pterygoid compartments by the lateral pterygoid and interpterygoid fasciae although fluid pressures or erosion could break down fascial boundaries.

A thickening was observed within the deep temporal fascia. American and British texts (Piersol, Morris, Gray, and Cunningham) neither describe nor illustrate this thickening. 
Waldeyer's textbook ('50) shows a portion of this structure labelled as a "faserzuge" between the temporal and buccinator muscles. Zenker (' $55 \mathrm{a}$ ) observed that a tendinous bundle (buccotemporal fascia) passed from the surface of the temporal muscle to the buccinator muscle, and that the fascia on the temporal muscle was tightly bound to this band. Hovelacque ('14) presented the first and, so far as I know, the only detailed description of this band. He described it as a tendinous layer between the temporal and buccinator muscles. This condensation, called here the temporo-buccinator band, is possibly a functional specialization. Two functions might be considered. The band may act to keep the fat pad between the lateral pterygoid, temporal, and masseter muscles as contractions of the masticatory muscles and movements of the coronoid process create forces which mold the posterior and superior extensions of the fat mass. Secondly, since the temporo-buccinator band passes between the temporal and the buccinator muscles, contraction of the temporal muscle will pull the central region of the buccinator muscle and the cheek lateralward. This would minimize the possibility of the cheek being caught between the molars in occlusion.

\section{SUMMARY}

The masticator space is a region bounded by fasciae which restrict the movement of fluid out of or into the space. In addition, the region is compartmentalized by fascial planes which inhibit the free movement of fluid within the space. These fasciae are related to the masticatory fat pad, the lateral pterygoid, and the temporal muscles. The fat pad is formed of a main mass or "body" from which extend buccal, pterygopalatine, temporal, and pterygoid processes. The fat pad is limited anteriorly by the masseteric fascia.

A lateral pterygoid fascia covers the external surface of the lateral pterygoid muscle. The deep temporal fascia covers the anterior surface of the temporal muscle and continues posteriorly over the medial surface of the muscle for a variable distance before fusing with the lateral pterygoid fascia. This 
fusion produces a pocket, opening anteriorly, in which the pterygoid process of the fat pad rests. The two fused layers posterior to the pocket form the sigmoidal septum which closes the mandibular notch. A prominent thickening, the temporobuccinator band, appears in the deep temporal fascia on the anterior surface of the temporal muscle.

On the basis of this fascial study, the deep temporal, lateral pterygoid, and interpterygoid fasciae separate a more medial pterygoid compartment from the more lateral region of the masticator space. The mandibular notch is not an open pathway from the deeper region of the space to the masseteric space. The fat pad is not in direct contact with the spaces of the pterygoid muscles. This compartmentalization of the masticator space should be understood in order to effect a proper drainage of the space with a minimum of tissue damage.

\section{LITERATURE CITED}

Batson, O. V. 1953 The temporalis muscle. Oral Surg., 6: 40-47.

Bransby-Zachary, G. M. 1948 The sub-masseteric space. Brit. Dent. J., 84: 10-13.

Brash, J. C. 1951 Cunningham's Text-book of Anatomy. 9th ed. Oxford Univ. Press, New York.

Coller, F. A., ANd L. Yglesias 1935 Infections of the lip and face. Surg. Gyn. and Obst., 60: 277-290.

Dingman, R. O. 1939 Management of acute infections of the face and jaws. Am. J. Orthodontics and Oral Surg., 25: 780-794.

Eisler, P. 1912 Die Muskeln des Stammes, in Bardeleben's Handbueh der Anatomie des Mensehen. vol. 2, sect. 2, part 1. G. Fischer, Jena, 1-705.

Forster, A. 1904 Ueber die morphologische Bedeutung des Wangenfettpfropfes. Seine Beziehungen zu den Kaumuskeln und zu der Glandula orbitalis. Arch. f. Anat. u. Entwklgseh., Anat. Abt., 197-298.

Fraxceschini, M. 1951 Ricerche anatomiehe sul corpo adiposo della guancia (corpus adiposum buccae) nell'uomo. Arch. Ital. Anat. Embriol., 56: 365-392.

Gilis, M., ANd M. Peyron 1905 La région parotidienne et l'espace maxillopharyngien. Montpellier Méd., 20: 348-371.

Goss, C. M. 1954 Gray's Anatomy of the Human Body 26th ed. Lea and Febiger, Phila.

Grodinsky, M., AND E. A. HoLtoke 1938 The faseiae and fascial spaces of the lead, neck and adjacent regions. Am. J. Anat., 63: 367-408.

Hexle, J. 1871 Handbuch der systematischen Anatomie des Menschen. Knochenlehre. F. Vieweg and Son, Braunschweig, 1: 1-310. 
HovelacQUe, A. $191 \pm$ Connexions du muscle temporal et du muscle buccinateur. Rapport du nerf buccal. Bibliog. Anat., $24: 15-20$.

Hovelacque, A., AND M. VirenqUe 1913 Les formations aponéurotiques region ptérygomaxillaire chez l'homme et chez quelques mammiferes. J. de l'Anat. et de la Physiol., 49 : 427-488.

Huber, G. C. 1930 Piersol's Human Anatomy. 9th ed. J. B. Lippincott Co., Phila.

Juvara, E. 1895 Anatomie de la région ptérygo-maxillaire. Thèse no. 186. Battaille and Cie, Paris, 1-65.

Kostrubala, J. G. 1945 Potential anatomical spaces in the face. Am. J. Surg., N. S. $68: 28-37$.

Scaman, R. E. 1919 On the development and finer structure of the corpus adiposum buccae. Anat. Ree., 15 : 267-287.

Schaffyer, J. P. 1953 Morris' Human Anatomy. 11th ed. The Blakiston Co., N. Y.

SEDAN, J., AND R. DE VERNÉJOUt 1914 Les ptérygoidiens; description, aponéuroses, rapports. Marseille Méd., 2: 565-684.

Sicher, H. 1952 Oral Anatomy. 2nd ed. C. V. Mosby, St. Louis, 1-529.

Sloman E. G. 1939 Anatomy and anesthesia of the buccinator (long buecal) nerve. J. Am. Dent. Assoc., 26: 428-434.

Waldeyer, A. 1950 Anatomie des Mensehen. Walter DeGruyter and Co., Berlin., 2: 1-523.

Zenker, W. 1955a Ü̉ber einige neue Befunde am M. Temporalis des Menschen. Zeitsch. f. Anat. u. Entwklgsch., 118: 355-368.

1955b Das "Spatium buccotemporale"' und die anderen Fascienräume der tiefen seitlichen Gesichtsregion. Ibid., 118: 371-390. 